\title{
O Cenário Brasileiro de Proteção à Violência na Infância e na Adolescência e a Agenda Governamental: Conquistas, Possibilidades e Desafios
}

\section{The Brazilian Scenario of Violence Protection in Childhood and Adolescence and the Government Agenda: Achievements, Possibilities and Challenges}

\author{
Brenda Souza de Castro \\ Universidade Federal de Viçosa (UFV) \\ E-mail: brendascastro03@gmail.com
}

Resumo: Os dados de violência contra crianças e adolescentes mostram uma triste realidade no Brasil. A Constituição de 1988 e o Estatuto da Criança e do Adolescente são grandes marcos na defesa e na garantia dos direitos para esse público, no entanto, os números expressivos de denúncias despertaram a necessidade de que o cuidado com o público infanto-juvenil se mantivesse em pauta na agenda governamental. O objetivo deste estudo foi compreender o que foi inserido na agenda governamental nos últimos dez anos (2009-2018), observando se houve conquistas, possibilidades de melhoria e quais os desafios. Foi realizado um estudo qualitativo, baseado em análise documental, bibliográfica e de conteúdo. Foram consultados os portais eletrônicos da Câmara dos Deputados, do Congresso Nacional, do Senado, do Ministério do Desenvolvimento Social e do Proteja Brasil nos quais foram encontradas quatro leis, três programas/ações sociais e nove projetos de lei em tramitação, todos voltados ao combate das diversas formas de violência contra crianças e adolescentes. Os programas/ações sociais evidenciaram-se como conquistas, os projetos de lei como possibilidades de suporte normativo para a criação de outras políticas públicas e os desafios estão em conscientizar o tripé EstadoFamília-Sociedade, diminuindo as ferramentas punitivas e fortalecendo as ferramentas educativas e preventivas.

Palavras-Chave: Agenda Governamental; Proteção; Violência; Crianças e Adolescentes.

\begin{abstract}
Data on violence against children and adolescents show a sad reality in Brazil. The 1988 Constitution and the Child and Adolescent Statute were great milestones in defending and guaranteeing rights for this part of the population, however, the expressive numbers of denunciations have awakened the need for care with the children and adolescents the government agenda. The objective of this study was to understand what has been inserted in the governmental agenda in the last ten years (2009-2018) with a view to solving this question, observing if there were achievements, possibilities of improvement and what the challenges. A qualitative study was conducted, based on documentary and content analysis. The electronic portals of the Chamber of Deputies, the National Congress, the Senate, the Ministry of Social Development and Proteja Brazil were consulted, where four laws, three social programs and
\end{abstract}


nine bills in progress, all focused on combat various forms of violence against children and adolescents. The social programs / actions were evidenced as achievements, the bills as possibilities of normative support for the creation of other public policies and the challenges are in raising awareness of the Family-State-Society tripod, reducing the punitive tools and strengthening the educational tools and preventive measures.

Keywords: Government Agenda; Protection; Violence; Children and Adolescents.

\section{Introdução}

Muitos são os problemas que assolam a infância e a adolescência brasileira, configurados por um cenário de violência psicológica, física, de abandono ou negligência que, infelizmente, ainda é uma realidade no Brasil. A Constituição de 1988 abarcou e abrangeu esta causa, até então não considerada em aspectos jurídicos que fossem específicos para esse público no país. O Brasil avançou constitucionalmente no contexto da cidadania ao assumir que o papel do cuidado para com as crianças e adolescentes é dever de todos, ou seja, do Estado, da família e também da sociedade, assegurando-lhes prioridade absoluta no atendimento das suas necessidades básicas além de salvaguardá-los de todas as formas de violência, descaso ou discriminação da qual possam estar expostos (Brasil, 1988).

Consoante ao direito previsto como forma de legalizar e se fazer cumprir o determinado pela Constituição de 1988, o Brasil, segundo o Fundo das Nações Unidas para a Infância UNICEF (2015), deixou para trás a Lei 6.697/79, o "Código de Menores", tida como discriminatória, repressiva e segregacionista para a infância, e criou, dois anos após a promulgação da Constituição, a Lei n ${ }^{\circ}$ 8.069/90, intitulada "Estatuto da Criança e do Adolescente (ECA)", que dispõe sobre a proteção integral dessa parcela da população.

O ECA, como novo marco legal destacou-se pelo respeito ao desenvolvimento de crianças e adolescentes e pelo compromisso em tratar a infância com prioridade absoluta (UNICEF, 2015), deixou-se de utilizar, propositalmente, o termo "menor", pois este possuía uma conotação pejorativa e incompatível, portanto, com a nova orientação jurídicoconstitucional, que preconiza alçar crianças e adolescentes à condição de titulares de todos os direitos fundamentais inerentes à pessoa humana (Digiacomo \& Digiacomo, 2011).

Revista Brasileira de Políticas Públicas e Internacionais, v. 04, n. 02, novembro/2019, pp. 115-132. 
Dentre as prioridades trazidas pelo ECA está o enfoque prioritário na formulação e na execução das políticas sociais públicas voltadas para as crianças e adolescentes (Brasil, 1990). Para o Unicef (2015) ainda há a necessidade de criação de políticas diferenciadas, capazes de promover a inclusão do público infanto-juvenil que têm seus direitos violados, conforme comprovado pelos números. Dados do documento "Cenário da Infância e Adolescência no Brasil" criado pela Fundação Abrinq (2017), mostram que o canal de denúncias Disque 100, serviço de atendimento do Governo Federal, registrou, só em 2015, mais de 150 mil denúncias em todo o Brasil referentes a crianças e adolescentes em situação de vulnerabilidade, o que inclui negligência, violência física, sexual, psicológica, entre outros crimes.

Santos e Kerbauy (2008) afirmam que, faz-se necessário a formulação de políticas públicas que possibilitem o desenvolvimento de crianças e adolescentes, fortalecendo-os para a vida em sociedade. É por meio dessas políticas pensadas para promoção e defesa dessa parcela da população que o ECA encontra amparo e abrangência para resolução dos problemas existentes.

Nessa vertente, considerando o número expressivo de denúncias de violências contra crianças e adolescentes nos últimos anos, este estudo propõe o seguinte questionamento: o que tem sido discutido na agenda governamental para solucionar essa demanda da população no período de 2009-2018? Importa saber, portanto, como o governo brasileiro tem atuado quanto a essa questão em termos de agenda, se existem políticas públicas sendo pensadas ou executadas em caráter preferencial e quais são as conquistas, as possibilidades e os desafios para melhoria desse cenário.

Para responder a essas questões o objetivo geral desse artigo é analisar a agenda governamental a respeito das medidas para conter a violência contra crianças e adolescentes nos últimos dez anos (2009-2018), evidenciando as conquistas, os desafios e as possibilidades de melhorias no cenário brasileiro. Como objetivos específicos, buscar-se-á:

a) Descrever o cenário da violência contra crianças e adolescentes no Brasil nos últimos dez anos (2009-2018);

b) Analisar as leis, os projetos de lei e políticas públicas criadas para amenizar o problema da violência contra crianças e adolescentes nesse intervalo de tempo.

Revista Brasileira de Políticas Públicas e Internacionais, v. 04, n. 02, novembro/2019, pp. 115-132. 


\section{Referencial Teórico}

\subsection{Agenda Governamental}

Os estudos sobre Agenda Governamental têm ganhado destaque no novo cenário da pesquisa sobre políticas públicas no Brasil (Brasil \& Capella, 2015). Todavia, antes de se pesquisar sobre entradas de temas e funcionamento, é necessário entender conceitualmente o que são as agendas governamentais.

Para Kingdon (2003), a agenda governamental ou agenda-setting é definida como o conjunto de assuntos sobre os quais o governo, e seus formuladores de políticas, concentram sua atenção num determinado momento. Nessa perspectiva, para que o governo concentre suas ações em algum tema é necessário que esse assunto chegue até ele de maneira significativamente capaz de se destoar de inúmeros outros assuntos que buscam solução através do Estado, voltando à atenção do mesmo para este tema em detrimento de outros. Para Capella (2005) atrair a atenção dos formuladores de política pode determinar o sucesso de uma questão no processo altamente competitivo de agenda, no qual diversas outras questões estão colocadas, aguardando a atenção destes formuladores.

Mas qual o caminho para que os assuntos cheguem como pauta à agenda governamental? Nessas circunstâncias, para se alcançar a atenção dos formuladores de políticas, exercem um papel muito importante os grupos dispostos a investir numa ideia, que tanto podem ser elementos da própria burocracia, como parlamentares, grupos de interesse ou membros da Academia (Gelinsky \& Seibel, 2008). O papel desses grupos é fundamental para garantir a sobrevivência de uma ideia e para colocá-la na agenda governamental (Gelinsky \& Seibel, 2008). Segundo Cunha e Zanetti (2017) as ações de públicos mobilizados que participam, deliberam e exercem controle público sobre os governos, possibilitam que suas demandas e opiniões sejam consideradas na tomada de decisões políticas.

No entanto, o alcance da notoriedade para um problema entrar para a agenda pode ser atingido através de alguns elementos que reforçam a relevância do assunto. Segundo Carvalho (2006), para que um problema tenha maior destaque para entrar na agenda ele precisa de confirmação por meio de dados estatísticos que apontem a demanda. Souza (2007) vai além ao

Revista Brasileira de Políticas Públicas e Internacionais, v. 04, n. 02, novembro/2019, pp. 115-132. 
CASTRO, Brenda Souza de. O Cenário Brasileiro de Proteção à Violência na Infância e na Adolescência e a Agenda Governamental

afirmar que existem três mecanismos que podem chamar a atenção para a necessidade de formulação de políticas públicas: (a) tornar públicos em indicadores que mostrem a dimensão do problema; (b) promover eventos que mostrem como a situação se repete ou é decorrente de desastres; e, (c) coletar feedbacks das políticas em vigor, que mostram a necessidade de correções.

Assim sendo, atingida a notoriedade por quaisquer dos meios citados, o tema proposto entra para a agenda de decisão do governo. Por meio de análise sobre o que foi discutido ou implementado através de leis, projetos de leis ou programas/ações governamentais torna-se possível a compreensão do quanto um assunto esteve em pauta na agenda-setting e como ele foi abordado durante determinado período de tempo. Logo, como é o foco deste estudo, é necessário que se entenda como o tema das crianças e adolescentes se faz presente enquanto pauta de uma agenda governamental.

\subsection{Crianças e Adolescentes na Agenda Governamental}

O ECA foi resultado da discussão entre governo e sociedade, por meio de fóruns, movimentos populares de rua, assim como denúncias que "pipocavam" nos meios de comunicação de massa relacionadas à educação, à saúde, ao trabalho e à violência contra as crianças (Alves, 2001). Para Perez e Passone (2010), o dispositivo representou uma profunda alteração representada em termos legislativos, normativos, culturais e conceituais para as diretrizes, políticas públicas e serviços destinados ao atendimento da criança e adolescente no Brasil.

A gama de direitos prevista pelo ECA aborda engajamentos referentes à prestação de serviços prioritários de assistência, saúde e educação como forma de enfrentamento da questão social a respeito das crianças e adolescentes em situações de vulnerabilidade (Mendonça, 2002). Todavia, torna-se preciso materializar os direitos das crianças e dos adolescentes através das ações concretas de políticas públicas (Benevides, Daniel \& Berwig, 2014).

Para tal, é necessário incorporar à agenda das políticas públicas sociais as crianças e adolescentes como sujeitos de direitos e, para que isso se materialize, espera-se do governo um conjunto de políticas sociais destinadas à inclusão do público infanto-juvenil por meio de ações

Revista Brasileira de Políticas Públicas e Internacionais, v. 04, n. 02, novembro/2019, pp. 115-132. 
planejadas e pensadas no sentido de garantir a vivência do acesso aos direitos (Benevides, Daniel \& Berwig, 2014).

Assim sendo, espera-se que a pauta dos direitos das crianças e dos adolescentes esteja, de maneira efetiva, inserida na agenda governamental, na tentativa de sanar as novas demandas desse público. Essa presença do assunto na agenda do governo é imprescindível pois, as diversas formas de violação dos direitos a que possam estar sujeitos, além de provocar um impacto no desenvolvimento enquanto pessoa, causa também uma catastrófica repercussão no comportamento do indivíduo na vida adulta (Nunes \& Sales, 2016).

\section{Procedimentos metodológicos}

Esta pesquisa caracterizou-se como qualitativa, onde a preocupação do pesquisador é, especificamente, o aprofundamento da compreensão de uma trajetória (Goldenberg, 2004). Quanto aos objetivos, essa pesquisa classificou-se como exploratória, pois estas são desenvolvidas com o objetivo de proporcionar uma visão geral, de tipo aproximativo, acerca de determinado fato (Gil, 2008). Aqui, isso se sintetizou em explorar a agenda governamental traçando uma trajetória sobre o que tem sido discutido quanto à prevenção da violência contra o público infanto-juvenil.

O método de análise se deu por meio de pesquisa documental e bibliográfica que conta, dentre outras fontes de dados, com a análise de arquivos públicos e relatórios de pesquisa baseados em publicações parlamentares (Marconi \& Lakatos, 2003). Neste trabalho esses documentos se traduziram em quatro leis, três programas/ações sociais e nove projetos de lei desenvolvidos para a defesa dos direitos das crianças e adolescentes, no intuito de combater a violência contra esse público nos últimos dez anos (2009-2018), de forma a se compreender quais foram as conquistas, as possibilidades e os desafios para diminuição da violência contra esse segmento social. O acesso aos documentos supracitados se deu através dos portais eletrônicos de domínio público da Câmara dos Deputados, do Congresso Nacional, do Senado e do Ministério do Desenvolvimento Social. Foi acessado também o Proteja Brasil, que se trata de um aplicativo publicamente disponibilizado.

Revista Brasileira de Políticas Públicas e Internacionais, v. 04, n. 02, novembro/2019, pp. 115-132. 
Para analisar os documentos, utilizou-se do método de análise de conteúdo que segundo Bardin (2002, p.42) se dá por um conjunto de técnicas de análise que permitem a inferência de conhecimentos relativos às condições de produção/percepção (variáveis inferidas) dessas mensagens. Neste estudo, a análise de conteúdo foi operacionalizada em categorias no intuito de facilitar a interpretação dos documentos encontrados, permitindo uma reflexão acerca da natureza e do propósito dos mesmos. São elas:

I. Natureza do Documento: Leis, Políticas Públicas ou Projetos de Lei.

II. Propósito do Documento: Punitivo, Educativo ou Preventivo.

\section{Resultados e discussões}

\subsection{Os dados da violência contra crianças e adolescentes}

Os dados da violência contra crianças e adolescentes são, infelizmente, alarmantes em nosso país e seu crescimento nos últimos anos acendeu um alerta entre os governantes para que algo seja feito em prol dessa parcela da população. Mesmo com a Constituição Federal de 1988 prevendo o dever de todos, incluindo família, Estado e sociedade de salvaguardá-los de quaisquer formas de violência, dando-lhes zelo e proteção, a negligência, a violência física, sexual e psicológica contra eles ainda existe e os coloca em situação de extrema vulnerabilidade, conforme mostram os dados da Tabela 1.

Tabela 1: Aumento percentual do número de casos notificados de violência contra crianças e adolescentes de 2009 a 2014

\begin{tabular}{c|c|c|c}
\hline $\begin{array}{c}\text { Tipo de Violência } \\
\text { contra Crianças e } \\
\text { Adolescentes }\end{array}$ & $\begin{array}{c}\text { Casos } \\
\text { Notificados 2009 }\end{array}$ & $\begin{array}{c}\text { Casos } \\
\text { Notificados 2014 }\end{array}$ & $\begin{array}{c}\text { Percentual de Aumento dos } \\
\text { Casos Notificados }\end{array}$ \\
\hline Assédio Sexual & 1.272 & 4.806 & $377,83 \%$ \\
\hline Estupro & 2.633 & 14.874 & $564,90 \%$ \\
\hline Exploração Sexual & 288 & 815 & $282,98 \%$ \\
\hline Negligência e Abandono & 3.630 & 21.751 & $599,20 \%$ \\
\hline Violência Física & 9.098 & 44.234 & $486,19 \%$ \\
\hline
\end{tabular}

Fonte: Elaborado pela autora com base nos dados da Fundação Abrinq, do Ministério da Saúde (MS)/Secretaria de Vigilância em Saúde (SVS) e do Sistema de Informação de Agravos de Notificação (SINAN).

Revista Brasileira de Políticas Públicas e Internacionais, v. 04, n. 02, novembro/2019, pp. 115-132. 
CASTRO, Brenda Souza de. O Cenário Brasileiro de Proteção à Violência na Infância e na Adolescência e a Agenda Governamental

É possível notar as porcentagens estarrecedoras no aumento das notificações de casos de diversos tipos de violência envolvendo crianças e adolescentes. Mesmo que o aumento desses números seja justificado, entre outros fatores, pela facilidade de acesso aos canais de denúncia no decorrer dos anos, principalmente pelo uso da tecnologia e mídias sociais, supor que esses números de 2014 talvez sempre existiram mas que nunca foram denunciados, só mostra que o tripé Estado-Família-Sociedade não está assegurando efetivamente os direitos dessas crianças e adolescentes.

Levando em consideração o poder do Estado de legislar e gerar ações sociais, através da inserção do problema em sua agenda, o que tem sido feito, discutido ou proposto para amenizar esse problema social? Partindo do que disse Souza (2007), que afirma que um dos mecanismos para que um assunto chame atenção e se torne pauta da agenda de governo é tornar público indicadores que mostrem a dimensão do problema, os dados da tabela 1, embora só estejam disponibilizados no período de 2009 a 2014, se juntaram a necessidade de se pensar leis ou políticas capazes de amenizar o problema, o que tem seu reflexo na agenda governamental até os dias atuais.

4.2. As conquistas, as possibilidades e os desafios para o combate a violência contra crianças e adolescentes no Brasil

No Quadro 1 evidenciam-se as leis de maior destaque que foram criadas na tentativa de sanar esse problema social nos últimos dez anos (2009-2018), buscando reforçar os cuidados com as crianças e adolescentes conforme previsto pelo ECA e punir com mais vigor os causadores das violências. Ao todo, quatro leis foram criadas.

Quadro 1: Leis federais criadas para combate à violência contra crianças e adolescentes no período de

\begin{tabular}{|c|c|c|c|c|}
\hline $\begin{array}{c}\text { Projeto } \\
\text { de Lei }\end{array}$ & Propositor & Ementa & $\begin{array}{c}\text { Norma } \\
\text { Gerada }\end{array}$ & Caráter \\
\hline PL & Câmara dos & Programa de Combate à Intimidação & $\begin{array}{c}\text { Lei } \mathbf{~ n}^{\mathbf{0}} \\
\mathbf{1 3 . 1 8 5}, \\
\text { de } 6 \text { de } \\
\text { novembro } \\
\text { de } 2015 .\end{array}$ & Punitivo \\
N $^{0} 68$ & Deputados & Sistemática (Bullying). & \\
de 2013 & & & & \\
\hline
\end{tabular}

Revista Brasileira de Políticas Públicas e Internacionais, v. 04, n. 02, novembro/2019, pp. 115-132. 


\begin{tabular}{|c|c|c|c|c|}
\hline $\begin{array}{c}\text { PL } \\
\text { No } 58^{\text {de } 2014}\end{array}$ & $\begin{array}{c}\text { Câmara dos } \\
\text { Deputados }\end{array}$ & $\begin{array}{l}\text { Estabelece o direito da criança e do } \\
\text { adolescente de serem educados e } \\
\text { cuidados sem o uso de castigos físicos } \\
\text { ou de tratamento cruel ou degradante. }\end{array}$ & $\begin{array}{c}\text { Lei da } \\
\text { Palmada: } \\
\text { no 13.010, }^{0} \text { de } 26 \text { de } \\
\text { junho de } \\
2014 .\end{array}$ & Punitivo \\
\hline $\begin{array}{c}\text { PL } \\
N^{o} 3792 \\
\text { de } 2015\end{array}$ & $\begin{array}{c}\text { Câmara dos } \\
\text { Deputados }\end{array}$ & $\begin{array}{l}\text { Estabelece o sistema de garantia de } \\
\text { direitos de crianças e adolescentes } \\
\text { vítimas e testemunhas de violência. }\end{array}$ & $\begin{array}{c}\text { Lei } \mathbf{n}^{\mathbf{0}} \\
\mathbf{1 3 . 4 3 1}, \\
\text { de } 4 \text { de abril } \\
\text { de } 2017 .\end{array}$ & Preventivo \\
\hline $\begin{array}{c}\mathrm{PL} \\
\mathrm{N}^{\mathrm{o}} 14 \\
\text { de } 2015\end{array}$ & $\begin{array}{c}\text { Câmara dos } \\
\text { Deputados }\end{array}$ & $\begin{array}{c}\text { Princípios e diretrizes para a } \\
\text { formulação e implementação de } \\
\text { políticas públicas para a primeira } \\
\text { infância. }\end{array}$ & $\begin{array}{c}\text { Marco } \\
\text { Legal da } \\
\text { Infância: } \\
\text { Lei no } \\
\text { 13.257, de } 8 \\
\text { de março de } \\
2016 .\end{array}$ & Preventivo \\
\hline
\end{tabular}

Fonte: Elaborada pela autora com base nos dados do portal eletrônico do Senado, Câmara dos Deputados e Congresso Nacional.

É possível notar que as quatro leis criadas foram aprovadas recentemente e abordam em seus textos punições a violências físicas ou psicológicas e mecanismos para que os direitos dessa parcela da população sejam garantidos, no intuito de sanar as lacunas deixadas pelo ECA de acordo com as novas demandas que foram surgindo.

No que tange à violência física criou-se a Lei da Palmada, no intuito de conscientizar e punir, se preciso, os causadores da agressão que estão, neste caso, inseridos no contexto familiar da criança ou adolescente, sejam eles os pais ou responsáveis. Quanto o cometimento de violência psicológica nota-se pela lei $\mathrm{n}^{\mathrm{o}}$ 13.185/15 a preocupação com o tema bullying, que pode ser cometido por familiares ou por terceiros, e que era inexistente como pauta até poucos anos atrás, demandando, portanto, uma legislação emergencial de combate. Ambas as leis, como se pode observar, apresentam um caráter punitivo, sendo aplicada, portanto, posteriormente a violência cometida.

Sobre as leis que tangenciaram a defesa dos direitos, o Sistema de Garantia de Direitos (SGD) embora tenha sido estabelecido e estruturado desde 2006 pelo Conselho Nacional dos Direitos da Criança e do Adolescente (Conanda), enfrentou a morosidade da tramitação o que fez com que ele só obtivesse sua normatização legal em 2017. Apesar da demora, sua criação

Revista Brasileira de Políticas Públicas e Internacionais, v. 04, n. 02, novembro/2019, pp. 115-132. 
ajudou a fortalecer o sistema na tentativa de assegurar a proteção máxima dessas crianças e adolescentes por meio de um trabalho em rede, envolvendo trabalho conjunto participativo com a sociedade civil e instituições de diversas áreas. O mesmo acontece com o Marco Legal da Infância de 2016 que dá diretrizes para as políticas públicas infantis, reconhecendo a importância das mesmas para o desenvolvimento das crianças, o que conversa diretamente com o que diz Benevides, Daniel e Berwig (2014) quando afirmam a necessidade de se materializar os direitos das crianças e dos adolescentes por meio das políticas públicas, cujas quais precisam ser pensadas e implementadas dentro dos direitos e garantias previstos pelo ECA. São, portanto, mecanismos de caráter preventivo, através da promoção dos direitos, no intuito de se evitar que a violência seja cometida.

Sabendo, portanto, que as leis são instrumentos reguladores, punitivos e/ou normatizadores dos conflitos sociais, as políticas públicas são, então, o meio pelo qual o governo executa ações que, dentro do que prevê ou sugere a lei, atuam prevenindo, punindo ou educando para evitar que a violência seja cometida ou, se já o foi, que seja denunciada e averiguada, garantindo assim a proteção das crianças e adolescentes em situação de vulnerabilidade. Essas políticas públicas podem ser entendidas como as conquistas brasileiras de combate à violência contra esse segmento social.

Nesse contexto, são apresentados no Quadro 2, os programas ou ações que foram desenvolvidas no período em questão com objetivo de salvaguardar essa parcela da população das mais variadas formas de violência.

Quadro 2: Programas ou ações de prevenção e combate à violência contra crianças e adolescentes no período (2009-2018)

\begin{tabular}{|c|c|c|}
\hline Programa ou Ação & $\begin{array}{c}\text { Ano de } \\
\text { Criação }\end{array}$ & Descrição \\
\hline Proteja Brasil & 2013 & $\begin{array}{l}\text { Aplicativo que permite o engajamento na proteção de } \\
\text { crianças e adolescentes por meio de denúncias diretas, } \\
\text { localização de órgãos de proteção e informações sobre } \\
\text { as diferentes violações. }\end{array}$ \\
\hline
\end{tabular}

Revista Brasileira de Políticas Públicas e Internacionais, v. 04, n. 02, novembro/2019, pp. 115-132. 
CASTRO, Brenda Souza de. O Cenário Brasileiro de Proteção à Violência na Infância e na Adolescência e a Agenda Governamental

\begin{tabular}{|c|c|c|}
\hline $\begin{array}{c}\text { Programa Criança } \\
\text { Feliz }\end{array}$ & 2016 & $\begin{array}{c}\text { Atenção às crianças em situação de vulnerabilidade e } \\
\text { fortalecimento do vínculo afetivo e do papel das } \\
\text { famílias no cuidado, na proteção e na educação das } \\
\text { crianças de } 0 \text { a } 6 \text { anos. O programa se operacionaliza } \\
\text { por meio de visitas domiciliares. }\end{array}$ \\
\hline $\begin{array}{c}\text { Instituição Parceira } \\
\text { da Primeira Infância }\end{array}$ & 2018 & $\begin{array}{c}\text { Desenvolver ações nas instituições de ensino superior } \\
\text { voltadas à primeira infância. }\end{array}$ \\
\hline
\end{tabular}

Fonte: Elaborado pela autora com base nos dados do portal eletrônico da Unicef e do Ministério do Desenvolvimento Social (MDS).

Nota-se que, o Proteja Brasil é um mecanismo de denúncia por meio de um aplicativo gratuito. Embora sua forma de ação seja posterior ao cometimento da violência, seu canal de denúncia se constitui com um avanço inquestionável na físcalização e punição dos envolvidos. A abrangência do aplicativo em uma parcela considerável do território nacional, aciona suportes de averiguação mais próximos da ocorrência, garantindo uma maior efetividade do atendimento à criança ou adolescente em situação de risco.

O Programa Criança Feliz foi desenvolvido no intuito de auxiliar as famílias com crianças de zero a seis anos na promoção do seu desenvolvimento integral, o que inclui o cuidado com as crianças em situação de vulnerabilidade através do auxílio aos pais e responsáveis nos cuidados e na proteção que são garantidas a essas crianças. Seu caráter é, portanto, preventivo.

Já o Programa Instituição Parceira da Primeira Infância preconiza o fortalecimento da causa nas instituições de ensino superior privadas, levando aos alunos dos cursos das áreas de Saúde, Pedagogia, Psicologia e Serviço Social uma disciplina com foco no desenvolvimento infantil capaz de contribuir na construção da consciência sobre a importância da primeira infância para o futuro, o que o caracteriza como um programa educativo, pois os futuros profissionais dessas áreas sairão com um olhar diferenciado para trabalhar com esse público.

Dentre as possibilidades de melhoria do cenário brasileiro da violência contra crianças e adolescentes ganham fôlego os inúmeros projetos de lei (PL's) no período de 2009-2018, os quais são evidenciados no Quadro 3 e que se encontram em tramitação até os dias atuais.

Revista Brasileira de Políticas Públicas e Internacionais, v. 04, n. 02, novembro/2019, pp. 115-132. 
CASTRO, Brenda Souza de. O Cenário Brasileiro de Proteção à Violência na Infância e na Adolescência e a Agenda Governamental

Quadro 3: Projetos de lei em tramitação para combate à violência contra crianças e adolescentes no período de 2009-2018.

\begin{tabular}{|c|c|c|}
\hline $\begin{array}{l}\text { Projeto de } \\
\text { Lei }\end{array}$ & Propositor & Ementa \\
\hline $\begin{array}{l}\text { PL N }^{\circ} 177 \text { de } \\
2009\end{array}$ & Senado & $\begin{array}{c}\text { Propõe agravar a pena dos crimes de estupro e atentado } \\
\text { violento ao pudor, quando cometidos contra criança, e dá } \\
\text { outras providências. }\end{array}$ \\
\hline $\begin{array}{l}\text { PL N }^{\circ} 507 \text { de } \\
2011\end{array}$ & Senado & $\begin{array}{l}\text { Estabelecer prioridade absoluta no julgamento dos crimes } \\
\text { envolvendo violência sexual contra criaç̧as ou adolescentes. }\end{array}$ \\
\hline $\begin{array}{l}\text { PL No } 74 \text { de } \\
2012\end{array}$ & Senado & $\begin{array}{l}\text { Currículos do ensino fundamental e médio incluam conteúdos, } \\
\text { relativos à prevenção da violência contra a criança (grifo } \\
\text { nosso). }\end{array}$ \\
\hline $\begin{array}{l}\text { PL No } 65 \text { de } \\
2015\end{array}$ & Senado & $\begin{array}{c}\text { Tipificar aplicação de qualquer forma de castigo corporal, } \\
\text { ofensa psicológica, tratamento cruel ou degradante à criança ou } \\
\text { adolescente com deficiência física, sensorial, intelectual ou } \\
\text { mental. }\end{array}$ \\
\hline $\begin{array}{l}\text { PL N } 51 \text { de } \\
2015\end{array}$ & Câmara & $\begin{array}{l}\text { Obriga os dirigentes de instituições de educação a notificarem } \\
\text { sinais de maus tratos envolvendo seus alunos. (grifo nosso) }\end{array}$ \\
\hline $\begin{array}{l}\text { PL N }^{\circ} 508 \text { de } \\
2017\end{array}$ & Senado & $\begin{array}{l}\text { Determina que os casos de suspeita ou confirmação de castigo } \\
\text { físico, de tratamento cruel ou degradante e de maus-tratos } \\
\text { contra criança ou adolescente e violência autoprovocada pelos } \\
\text { mesmos sejam obrigatoriamente comunicados ao Conselho } \\
\text { Tutelar. }\end{array}$ \\
\hline $\begin{array}{l}\text { PL No } 9188 \\
\text { de } 2017\end{array}$ & Câmara & $\begin{array}{l}\text { Acrescenta parágrafo ao art. } 130 \text { do ECA para garantir a } \\
\text { proteção da integridade psíquica e física da criança. }\end{array}$ \\
\hline $\begin{array}{l}\text { PL N }^{\mathrm{o}} 202 \mathrm{de} \\
2017\end{array}$ & Senado & $\begin{array}{c}\text { Obriga os profissionais de saúde notificarem à autoridade } \\
\text { policial os casos de violência contra a dignidade sexual de } \\
\text { crianças ou adolescentes. }\end{array}$ \\
\hline $\begin{array}{l}\text { PL No } 10697 \\
\text { de } 2018\end{array}$ & Câmara & $\begin{array}{c}\text { Aumenta a pena dos crimes cometidos contra crianças e } \\
\text { adolescentes. }\end{array}$ \\
\hline
\end{tabular}

Fonte: Elaborado pela autora com base nos dados do portal eletrônico do Senado, Câmara dos Deputados e Congresso Nacional.

Todos esses projetos, em diferentes anos mostram o quanto o tema da violência contra crianças e adolescentes esteve e está presente na agenda governamental brasileira. As tramitações que são, por vezes, morosas, mostram a tentativa por parte do Estado, pressionado socialmente pelos números crescentes da violência infanto-juvenil, de sanar algumas lacunas deixadas pelo ECA, criando leis capazes tanto de prevenir que a violência seja cometida quanto de punir efetivamente os culpados pela mesma, seja ela qual for.

Revista Brasileira de Políticas Públicas e Internacionais, v. 04, n. 02, novembro/2019, pp. 115-132. 
CASTRO, Brenda Souza de. O Cenário Brasileiro de Proteção à Violência na Infância e na Adolescência e a Agenda Governamental

Outro fato bastante curioso e que merece destaque é que os projetos de leis supracitados preconizam a inserção da prevenção e da informação dentro das escolas, como é o caso do PL N 74 e $N^{0}$ 51, que envolvem efetivamente, o pilar da sociedade na função de salvaguardar as crianças e os adolescentes incluindo, nos currículos de educação nacional, a conscientização, o acesso à informação tanto sobre os tipos de violência quanto sobre os canais de denúncia, bem como a obrigatoriedade dos responsáveis da instituição em comunicar possíveis sinais de maus-tratos.

Esses PL's assumem, portanto, um caráter educativo e preventivo, o que conversa diretamente com o Programa Criança Feliz e o Programa Instituição Parceira da Primeira Infância. Isso porque, esses programas já vêm colocando em prática a necessidade de se atrelar o fator educação em suas diversas formas para que pais, professores, alunos e sociedade, deem o devido suporte na prevenção e combate da violência contra o público infanto-juvenil.

O PL N 202 amplia ainda mais o pilar social na proteção dos direitos das crianças e dos adolescentes quando propõe a obrigatoriedade também dos funcionários de estabelecimento de saúde em comunicar imediatamente as autoridades em casos de suspeitas de violência contra, dentre outros públicos, as crianças e os adolescentes.

Sobre esses projetos de lei, fica evidenciado que, dentro do que prevê a $\mathrm{CF} / 88$, que assegurou a garantia dos direitos da infância e da adolescência em três pilares, sendo eles Estado, família e sociedade, eles traduzem uma possibilidade de integrar a sociedade, de modo que, mesmo que obrigatoriamente, ela participe de forma efetiva na proteção dessa parcela vulnerável da população, principalmente naqueles setores com contato mais direto com as crianças e adolescentes, como educação e saúde. Assim sendo, a aprovação desses PL's podem significar um suporte normativo para a criação de outras políticas públicas que abarquem a causa.

Todavia, o caráter punitivo dos PL's No $177, \mathrm{~N}^{\mathrm{o}} 507, \mathrm{~N}^{\mathrm{o}} 65$ e $\mathrm{N}^{\mathrm{o}} 10.697$ merecem atenção. A educação, embora fundamental, não soluciona sozinha os crimes já cometidos, que necessitam da punição dos envolvidos. Esses PL's, dentre seus propósitos, evidenciam que as formas de punição já vigentes não estão sendo suficientes para solucionar o problema. Eles preveem, portanto, punições que vão desde o aumento da pena para crimes contra a parcela

Revista Brasileira de Políticas Públicas e Internacionais, v. 04, n. 02, novembro/2019, pp. 115-132. 
infanto-juvenil da população até a prioridade absoluta dos julgamentos, o que, se aprovado, complementará a gama de prioridades absolutas do ECA, que já prevê a prioridade absoluta no direito à vida, à saúde, à alimentação, à educação, ao lazer, à profissionalização, à cultura, à dignidade, ao respeito, à liberdade e à convivência familiar e comunitária das crianças e dos adolescentes (Brasil, 1990).

Neste contexto de conquistas e possibilidades, identificar e encarar os desafios tornase crucial. As leis, programas e ações conquistados, bem como os projetos de leis existentes que embora sofram com a burocracia e a morosidade dos trâmites públicos, só pelo fato de terem despertado a necessidade de diálogo e de ação no combate a violência infanto-juvenil para além do que prevê o ECA já os tornam bastante significativos e mostra que existe uma agenda sobre a temática.

Dessa forma, analisando tanto os projetos em tramitação quanto o que já se tem tramitado e operante, os desafios para melhorar ou amenizar o problema da violência contra crianças e adolescentes estão, portanto, em conscientizar o tripé Estado-Família-Sociedade a trabalhar integradamente, seja por meio de contato direto ou por meio de tecnologia, que é um destaque na geração atual, para que a utilização de ferramentas punitivas sejam cada vez menos necessárias ao passo que as ferramentas preventivas e educativas se enraízem e ganhem força na sociedade brasileira.

\section{Considerações finais}

Em suma, a importância desse estudo está no conhecimento do cenário brasileiro de proteção à violência na infância e na adolescência dentro do que tange a agenda de governo, permitindo-nos conhecer quais são os avanços e gargalos da temática. Dessa maneira, o questionamento sobre quais são, portanto, as conquistas, as possibilidades de melhoria e os desafios a serem considerados, nos permite uma reflexão do que ainda pode e deve melhorar para amenizar o cenário apresentado.

Revista Brasileira de Políticas Públicas e Internacionais, v. 04, n. 02, novembro/2019, pp. 115-132. 
O que se observou durante todo o estudo é que o assunto do combate à violência contra crianças e adolescentes se manteve em pauta na agenda governamental durante toda década analisada (2009-2018), sendo notada a presença de leis, projetos de leis, programas e ações desde o início do período demarcado até os dias atuais. Isso se dá, seguramente, pela importância que as crianças e os adolescentes têm para o país, de modo que, qualquer forma de negligencia por parte do governo, representa um descaso com o futuro da nação.

Por meio da presença constante do problema na pauta governamental, o alcance da criação de leis como a Lei da Palmada, do Bullying, do Sistema de Garantia de Direitos, que normatiza o trabalho em rede e, do Marco Legal da Infância mostram o avanço que o Brasil alcançou para resolver os novos problemas que surgem, como a questão do bullying e a ampliação das formas de se garantir os direitos e cuidados dos quais as crianças e os adolescentes são assegurados pelo ECA, mas que estavam passíveis de lacunas deixadas pelo mesmo.

Todavia, como as leis apenas instrumentalizam, são as políticas públicas quem efetivam as ações. Assim, em termos de conquistas, a criação do sistema Proteja Brasil representa, indubitavelmente, o quanto as tecnologias podem ajudar nas redes de proteção contra violências infanto-juvenis, nos permitindo acesso e voz numa proporção consideravelmente maior que anos atrás. O Programa Criança Feliz, bem como o Programa Instituição Parceira da Primeira Infância sinalizam a importância que o cuidado das famílias, o conhecimento de causa dos futuros profissionais que lidarão diretamente com o público infanto-juvenil e as escolas tem no combate a violência contra as crianças e adolescentes.

Quanto às possibilidades, embora haja morosidade das tramitações, que podem acontecer pela própria burocracia do país, por uma diminuição da pressão popular sobre os governos ou por outros temas de urgência que chegam à agenda governamental e demandam os esforços dos legisladores para outros assuntos de prioridade do momento, o empenho em propor projetos de lei em fechar as lacunas merece reconhecimento.

A proposta de inserção do assunto da violência contra crianças e adolescentes dentro da própria escola, como assunto transversal no currículo da educação, permitindo que os menores tomem conhecimento das variadas formas de violência a que estão sujeitos e os canais de

Revista Brasileira de Políticas Públicas e Internacionais, v. 04, n. 02, novembro/2019, pp. 115-132. 
denúncia disponíveis para defendê-los será, se aprovado, uma forma de conscientizar tanto a criança e o adolescente, quanto as suas famílias. As propostas de obrigatoriedade tanto das escolas quanto dos profissionais de saúde em notificarem casos suspeitos, também configurarão caso sejam aprovadas, um fortalecimento do trabalho em rede e um suporte para se incrementar ou criar novas políticas públicas.

No que tange aos desafios, a ressalta se dá no quanto ainda necessita-se de ferramentas punitivas. A presença de leis e projetos de lei que propõem penas mais severas e julgamentos prioritários, atrelados aos números da violência apresentados no estudo, mostram que ainda existem lacunas a serem fechadas. As políticas públicas são, portanto, o caminho para se efetivar ações, valendo-se de ferramentas educativas e preventivas para minimizar a existência de novos casos de violência.

Todavia, o caminho da conscientização nem sempre é fácil. Os desafios estão em promover uma integração das ações, atrelada ao suporte da tecnologia, capaz de cooptar esforços do Estado, das famílias, da sociedade, dos estabelecimentos de saúde e também das escolas, trabalhando de maneira conjunta, em diferentes esferas governamentais, com o intuito de fortalecer a rede de proteção, tratando irrestritamente, dentro do que cabe a cada um, prevenir, apoiar, conscientizar e punir as violências praticadas contra as crianças e os adolescentes.

\section{Referências}

Alves, E. S. (2001, janeiro/julho). Infância e Juventude: Um breve olhar sobre as Políticas Públicas no Brasil. Revista Linhas. V. 2, n. 2.

Bardin, L. (2002). Análise de conteúdo. Brasil: Edições.

Benevides, J., Daniel, R., \& Berwig, S. E. (2014). Políticas Públicas e Estatuto da Criança e do Adolescente - Materialização dos Direitos das Crianças e Adolescentes. III Seminário Internacional de Ciências Sociais - Ciência Política, Universidade Federal do Pampa, São Borja, RS, Brasil.

Brasil. (1988). Constituição da República Federativa do Brasil. Brasília: Senado Federal.

Revista Brasileira de Políticas Públicas e Internacionais, v. 04, n. 02, novembro/2019, pp. 115-132. 
CASTRO, Brenda Souza de. O Cenário Brasileiro de Proteção à Violência na Infância e na Adolescência e a Agenda Governamental

Brasil. (1990). Lei $n^{\circ}$ 8.069, de 13 de julho de 1990. Estatuto da Criança e do Adolescente. Brasília: Diário Oficial [da República Federativa do Brasil].

Brasil, F. G., \& Capella, A. C. N. (2015). O Processo de Agenda-Setting para os Estudos das Políticas Públicas. RP3 - Revista de Pesquisa em Políticas Públicas, nº 01, 41-63.

Capella, A. C. N. (2005). Formação da agenda governamental: perspectivas teóricas. Anais do XXIX Encontro Anual da ANPOCS. Caxambu, MG, Brasil.

Capella, A. C. N. (2006). Perspectivas Teóricas sobre o Processo de Formulação de Políticas Públicas. Revista Brasileira de Informação Bibliográfica em Ciências Sociais, v. 61, 25-52.

Carvalho, G. C. A. (2006, agosto/dezembro). Juventude e Políticas Públicas: Mero destaque na agenda pública ou garantia de direitos? Revista Eletrônica dos Pós-Graduandos em Sociologia Política da UFSC, 2 (2), 163-175.

Cirqueira, A. P. (2007). Violência física intrafamiliar: as percepções dos adolescentes do Programa Sentinela de Itaborai sobre a violência física sofrida. (Dissertação de Mestrado) Pontifícia Universidade Católica do Rio de Janeiro, Departamento de Serviço Social, Rio de Janeiro.

Cunha, E.S. M., \& Zanetti, D. G. (2017). Participação e Influência na Agenda Governamental: o caso da assistência social. Anais do $10^{\circ}$ Encontro da Associação Brasileira de Ciência Politica, Belo Horizonte, MG, Brasil.

Digiácomo, M. J., \& Digiácomo, I de A. (2011). ECA - Estatuto da Criança e do Adolescente anotado e interpretado. $2^{\mathrm{a}}$ Ed. São Paulo: FDT.

Fundação Abrinq (2017). Cenário da Infância e Adolescência no Brasil, Nywgraf Editora Gráfica.

Gelinski, C. R. O. G., \& Seibel, E. J. (2008, abril/outubro). Formulação de politicas publicas: questoes metodologicas relevantes. Revista de Ciencias Humanas, v. 42, n. I e 2, 227-240.

Gil, A. C. (2008). Métodos e Técnicas de Pesquisa Social. 6 ed. São Paulo: Editora Atlas

Goldenberg, M. (2004). A Arte de Pesquisar: como fazer pesquisa qualitativa em ciências sociais. $8^{\mathrm{a}}$ Ed. Rio de Janeiro/São Paulo: Editora Record.

Kingdon, J. (2003). Agendas, Alternatives, and Public Policies. 3a. Ed. New York: Harper Collins.

Revista Brasileira de Políticas Públicas e Internacionais, v. 04, n. 02, novembro/2019, pp. 115-132. 
Marconi, M. de A., \& Lakatos, E. M. (2003). Fundamentos de Metodologia Científica. $5^{\text {a }}$ Ed. São Paulo: Editora Atlas.

Mendonça, M. H. M. (2002). O desafio da política de atendimento à infância e à adolescência na construção de políticas públicas equitativas. Cad. Saúde Pública, Rio de Janeiro, vol. 18 [suplemento], 113-120.

Nunes, A. J., \& Sales, M. C. V. (2016). Violência contra crianças no cenário brasileiro. Ciência \& Saúde Coletiva, 21 (3), 871-880

Perez, J. R. R., \& Passone, E. F. (2010, maio/agosto). Políticas Sociais de Atendimento às Crianças e aos Adolescentes no Brasil. Cadernos de Pesquisa, 40 (140), 649-673.

Santos, R., \& Kerbauy, M. T. M. (2008). Políticas Públicas Para Crianças e Adolescentes: Violência, Conflito Familiar E Distúrbios Escolares. Revista do Laboratório de Estudos da Violência e Segurança, nº 02, 59-81.

Souza, C. (2007). Estado da arte da pesquisa em políticas públicas. In: Hoch-Man, G., Arretche, M. \& Marques, E. Políticas públicas no Brasil. Rio de Janeiro: Editora FOCRUZ.

Unicef, Fundo das Nações Unidas para Infância. (2015). ECA 25 anos: avanços e desafios para infância e adolescência no Brasil.

Revista Brasileira de Políticas Públicas e Internacionais, v. 04, n. 02, novembro/2019, pp. 115-132. 